\title{
EDITORIAL
}

\section{Innovations in Obesity and Metabolic Surgery: Boon or Bane?}

\author{
REYNU R, KOSAINR \\ Minimally Invasive, Upper Gastrointestinal and Bariatric Surgery Unit, Department of \\ Surgery, Faculty of Medicine, Universiti Kebangsaan Malaysia Medical Centre, Jalan \\ Yaacob Latif, Bandar Tun Razak, 56000 Cheras, Kuala Lumpur, Malaysia.
}

There are numerous studies over the past few decades that reiterate the positive points of Obesity and Metabolic Surgery. It's ability to provide a relatively more sustainable weight loss over a longer period of time, improvement in quality of life and weight-related comorbidities namely Type 2 Diabetes Mellitus are among a few to boast. However, as with any invasive procedure, Obesity and Metabolic Surgery is not free of possible complication risks, the main reason for which there has been a major push for improvements in efficacy and innovation for better and safer surgical weight loss options. In the era of "healthcare at your fingertips", a simple Google search will be able to enlighten just anyone on the available options making it possible for an individual to "negotiate" or "bargain" with their surgeon before making a final decision. The four most well researched and documented weight loss procedures are Laparoscopic Sleeve Gastrectomy (LSG), Laparoscopic Roux-En-Y gastric Bypass (LRYGB), Biliopancreatic
Diversion (BPD) and Laparoscopic Adjustable Gastric Banding (LAGB) (Buchwald et al. 2004). Look a little closer and you will not be able to turn away from being a tad bit curious about a few "new kids on the block" such as Laparoscopic Mini Gastric Bypass, Laparoscopic Sleeve Gastrectomy with Proximal Jejunal Bypass, Laparoscopic Banded Roux-En-Y Gastric Bypass and some of the less invasive endoluminal procedures including a recent FDA approved percutaneous aspiration device called Aspire Assist that has garnered much interest as well as criticism at the same time (Lee et al. 2014; Kumar 2016; Forssell \& Norén 2015). Surgeons from all over the world, their institutions, and the supporting industry laud the excitement surrounding innovation in Obesity and Metabolic Surgery. A sentiment shared by consumers who perceive "new" as synonymous with improved.

However, the speed of which the "Innovation Train" has been clocking in recent years has made many weiry, causing them take a step back and

Address for correspondence and reprint requests: Dr. Reynu Rajan, Department of Surgery, Faculty of Medicine, Universiti Kebangsaan Malaysia Medical Centre, Jalan Yaacob Latif, Bandar Tun Razak, 56000 Cheras, Kuala Lumpur, Malaysia. Tel: +603-91456201 Fax: +603-91456684 E-mail: dr.reynu@gmail.com 


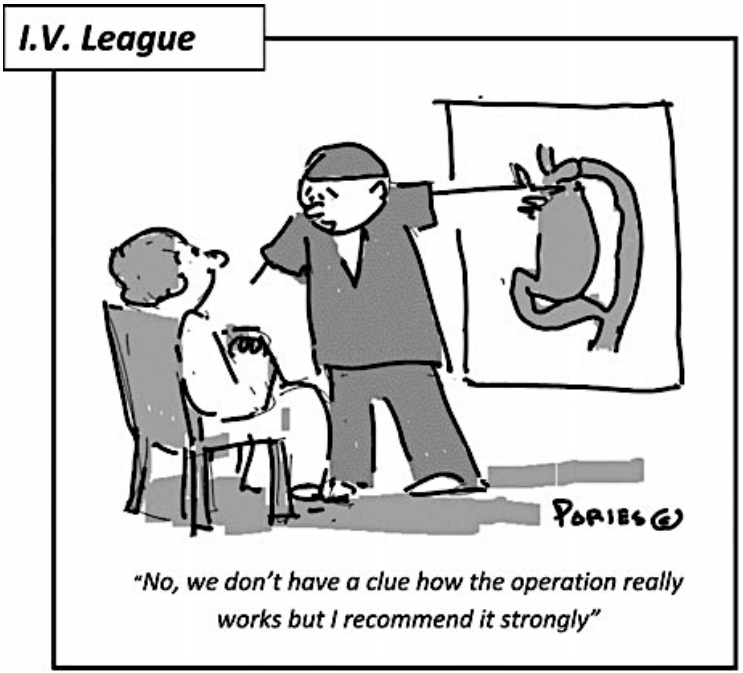

Figure 1: Walter Pories Cartoon (Carlson 2015)

look at the whole fiasco from a bird's eye perspective. Would it not be more reasonable to delineate the mechanisms of existing bariatric procedures before new ones are pushed into the open? Better understanding of the relevant pathophysiology would allow design and redesign of future bariatric procedures to proceed and progress on a much more respectable and believable foundation. Walter Pories a world reknown, well respected and much loved Bariatric Surgeon with an flair for drawing brilliant cartoons about every day life as a surgeon, beautifully ilustrates this lack of understanding of the underlying mechanism of Obesity and Metabolic Surgery in a Cartoon (Figure 1).

While it is undeniable and irrefutable that surgery is a valid option for treatment of obesity and obesity related metabolic syndrome, our knowledge of how bariatric procedures work needs much more "work" in itself. Many of the so-called "published reports" pertaining to novel therapies boasts fantastic early outcome, with intermediate or long term data no where to be seen despite being in the market for more than 5 yrs. Poor outcome or unwarranted complications attributed to the rapid turnover of novel procedures especially those without rigorous or independent cross check mechanisms could pose a negative anddetrimental effect on health care access for patients suffering with obesity and obesity related diseases. For a tiny developing country in South East Asia country like Malaysia, the end effect of such a catastrophe could plummet our healthcare economy.

\section{REFERENCES}

Buchwald, H., Avidor, Y., Braunwald, E., Jensen, M.D., Pories, W., Fahrbach, K., Schoelles, K. 2004. Bariatric surgery: a systematic review and meta-analysis. JAMA 292(14): 1724-37.

Carlson, M.A. 2015. Research priorities in bariatric surgery: misplaced emphasis on innovation? Ann Surg 261(2): e58-e59.

Forssell, H., Norén, E. 2015. A novel endoscopic weight loss therapy using gastric aspiration: results after 6 months. Endoscopy 47(1): 68-71. 
Kumar, N. 2016. Weight loss endoscopy: Development, applications, and current status. World J Gastroentero/ 22(31): 7069-79.

Lee, W.J., Chong, K., Lin, Y.H., Wei, J.H., Chen, S.C. 2014. Laparoscopic sleeve gastrectomy versus single anastomosis (mini-) gastric bypass for the treatment of type 2 diabetes mellitus: 5 -year results of a randomized trial and study of incretin effect. Obes Surg 24(9): 1552-62.

Received: 20 February 2017

Accepted: 16 May 2017 